\title{
Effectiveness of Mindfulness Techniques in Decreasing Anxiety and Depression in Women Victims of Spouse Abuse
}

\author{
Shahrbanoo Ghahari ${ }^{1,2}$, Nooshin Khademolreza ${ }^{3}$, Fatemeh Sadeghi Poya ${ }^{4}$, \\ Siamak Ghasemnejad ${ }^{5}$, Bahram Gheitarani ${ }^{6}$ and Mohammad Reza Pirmoradi ${ }^{7 *}$ \\ 'Department of Mental Health, Iran University of Medical Sciences (IUMS), Center of Excellence in Psychiatry, \\ School of Behavioral Sciences and Mental Health, Tehran, Iran; ghahhari.sh@iums.ac.ir \\ 2Psychiatry and Behavioral Sciences Research Center, Addiction Institute, \\ Mazandaran University of Medical Sciences, Sari, Iran \\ ${ }^{3}$ Department of Social Psychiatry, Iran University of Medical Sciences (IUMS), Center of \\ Excellence in Psychiatry, School of Behavioral Sciences and Mental Health, Tehran, Iran \\ ${ }^{4}$ Department of Psychology, Payame Noor University, Asalooieh, Iran \\ ${ }^{5}$ Department of Psychology, Islamic Azad University, Science and Research Branch, Sari, Iran \\ ${ }^{6}$ Department of Psychology, Islamic Azad University, Tonekabon Branch, Tonekaboon, Iran \\ ${ }^{7}$ Department of Clinical Psychology, Iran University of Medical Sciences (IUMS), Center of Excellence in Psychiatry, \\ School of Behavioral Sciences and Mental Health, Tehran, Iran; mr.pirmoradi@chmail.ir
}

\begin{abstract}
Psychiatric Disorders such as depression and anxiety are outputs of domestic violence and victims should be treated using medical and nonmedical treatment. The main purpose of this study is to investigate effectiveness of mindfulness-based cognitive therapy in reducing anxiety and depression of women victims of domestic violence in Tehran. The study is an empirical research in kind of pretest-posttest plan with control group. Statistical population consists of women victims of domestic violence in Tehran referred to several psychiatric clinics in Tehran for treatment by 2015. Statistical sample consists of 30 women selected randomly, who were placed in two groups each group with 15 members. Experimental group was under intervention of mindfulness-based cognitive therapy for 8 sessions and control group was in waiting list. Both groups fulfilled Beck's Depression Inventory (BDI) and Spielberger's State-Trait Anxiety Inventory (STAI) in final step and end of treatment. Obtained data was analyzed using ANOVA and using SPSS22 software. The obtained results from the study show that there is significant difference between two experimental and control groups in terms of depression and anxiety after mindfulness-based cognitive therapy intervention $(\mathrm{p}<001)$. The obtained results from the study show that mindfulness-based cognitive therapy can affect reduction of anxiety and depression of women victims of domestic violence.
\end{abstract}

Keywords: Anxiety, Depression, Mindfulness-Based Cognitive Therapy, Women Victims of Domestic Violence

\section{Introduction}

Domestic violence is a kind of physical, sexual or emotional-mental abuse created by close partner and is recognized across the world as a problem with public health ${ }^{1}$. Women victims of violence are more exposed to mental damages because of being responsible for different functions as spouse, mother and social functions ${ }^{2}$. A review of statistics of violence against women at the world shows that in different points of the world, $16-25 \%$ of women suffer from physical abuses by their life partners and at least, one out of five women is exposed to such

* Author for correspondence 
violence in her life ${ }^{3}$. Studies in different countries show that violence against women can result in many negative effects for them and women victims of violence are involved inside expanded physical and mental disorders. Hence, some studies have an emphasis on prevalence of symptoms of anxiety ${ }^{4,5}$ and depression ${ }^{6,7}$ in women victims of domestic violence. Gilroy et al. ${ }^{8}$ have found that among women victims of domestic violence referred to health centers, the most common disorder has been anxiety and depression. Moreover, obtained results from studies of Ghahari et $\mathrm{al}^{9}$ and Bradley, Schwartz and Kaslow ${ }^{10}$ show that depression and suicide symptoms in women victims of domestic violence are more than other women. Anxiety is one of the most common mental disorders, in which a sense of worry and threat from the emergence of an uncertain and ambiguous danger is tangible ${ }^{11}$. Anxiety is along with physical symptoms (such as trembling hands and feet, palpitations, nausea, and diarrhea) and cognitive symptoms (such as concentration, alert, feel confusion, fear of going crazy), cognitive problems (such as depersonalization and derealization) and behavioral problems (such as irritability and stillness) ${ }^{12}$.

Depressed mood and inability to enjoy are key symptoms of depression. Almost all depressed patients complain about the decline of their energy. $80 \%$ of patients complain about sleep disorders. Also, loss of appetite, difficulty concentrating, feelings of worthlessness, anxiety, thoughts of death or suicidal tendencies is common among these patients ${ }^{13}$. Mindfulness is an approach can encompass the presence of mind in present time and non-judgmental look to the experiences, in combination with meditation and specific mental orientation to an experience ${ }^{14}$. Mindfulness-based training, along with integration of meditation and physical checking techniques, can help raise of awareness of thoughts, feelings, and automated physical senses, so that one can go out of the automated mode using the techniques and behave mindfully and be in moment ${ }^{15}$. Hartmann et al. ${ }^{16}$ have found in a study that mindfulness based on stress reduction can affect the reduction of emotional distress (depression and anxiety) in types of chronic diseases positively. According to the positive effects of mindfulness-based cognitive therapy in the field of treatment of psychiatric disorders, the aim of this study is to investigate the effectiveness of mindfulness-based cognitive therapy in reducing anxiety and depression of a women victim of domestic violence in Tehran.

\section{Research Methodology}

The present study is an empirical research in a kind of pretest-posttest with the control group. Statistical population consists of women victims of domestic violence in Tehran referred to several psychiatric clinics in Tehran for treatment by 2015. Out of the individuals, those who were ready to participate in this study were asked to fulfill Beck's Depression Inventory (BDI) and Spiel Berger's State-Trait Anxiety Inventory (STAI). Out of the people, those with high scores in depression and anxiety inventories, 30 women were selected randomly and were placed in two groups each group with 15 members. The experimental group was under the intervention of mindfulness-based cognitive therapy for 8 sessions and control group was in waiting list until the end of intervention. Obtained data were analyzed using ANOVA and using a SPSS22 software.

\section{Instrument}

Following instruments have been used for purpose of data collection.

\subsection{Beck's Depression Inventory 2 (BDI-II)}

Beck's Depression Inventory- $2^{17}$ is a 21 -item inventory and is one of the most important self-report instruments to measure depression. The inventory has good validity and reliability ${ }^{18}$. Validity and reliability of the inventory in Iran are measured in a study. Cronbach alpha of the inventory is equal to 0.91 and its reliability is reported to 0.96 using retest method ${ }^{19}$.

\subsection{Spielberger's State-Trait Anxiety Inventory (STAI)}

The inventory was made by Spielberger et al. in 1970 and was revised by 1983. Items 1-20 measure state anxiety and items 21-40 measure trait anxiety. Scoring is in this manner that each item of the test gets score 1-4 based on the answer of the respondent with the difference that sentences with the concept of presence of anxiety are scored from 1 to 4 and sentences without content of anxiety are scored from 4 to 1 (reversely) and then, total value of test in each scale is estimated. Hence, scores of each state and trait scale can be in the range of 20-80. The scores of each interpretation of scores are as follows: 
State anxiety: weak (20-31); lower moderate (32-42); higher moderate (43-53); relatively high (54-64); high (63-72) and very high (over 76).

Trait anxiety: weak (20-30); lower moderate (32-42); higher moderate (43-52); relatively high (53-62); high (63-72) and very high (over 73).

In a study, reliability coefficient is obtained to 0.81 using the internal consistency of Cronbach alpha and the value has been significant statistically. After implementation of the study for the whole sample, estimated reliability was obtained to $0.79^{20}$. Moreover, Tol et al. ${ }^{21}$ reported validity and reliability of the instrument to $97 \%$.

In study of Mahram ${ }^{22}$ (1993), Iranian validation and normalization of this test is done in Mashhad. In this study, the reliability of state anxiety is obtained to $91 \%$ and for trait anxiety; it is obtained to $90 \%$. For total test, reliability is reported by $94 \%$. Using criterion method, the validity of the test is also confirmed at the same time.

\subsection{Intervention Package}

Treatment package of the present study is implemented based on mindfulness-based cognitive therapy protocol for generalized anxiety disorder ${ }^{4}$ in the form of 8 sessions with $45 \mathrm{~min}$ per session as follows:

Session 1: explaining 8-session content of MBCT plan; explaining elements of CBT such as behavior-emotionthought-feeling cycle; meditation and physical checking; beginner's mind practice, eating a raisin with awareness and giving homework.

Session 2: 3-Minute Breathing Space (3MBS); training consciousness during activities; training in awareness and concentration on functions of the mind (Being Mode and Doing Mode); body scan meditation; training lack of judgment and criticism of thoughts and feelings of self; training observation of individuals, feelings and behaviors; checking homework of last session and giving new homework.

Session 3: explaining emotions and their dimensions; training in breathing with focusing on some parts of the body, in which stress and emotion are felt; awareness of emotions and those emotions are not good or bad and are just emotions; increase in self-consciousness of body, emotions and responses to them; conscious breathing and training change of point of view of thoughts, emotions and experiences and giving homework.

Session 4: training presence in being mode; mindfulness of the body; mindfulness of thoughts; doing an enjoyable task; making conscious and mindful decisions and giving homework.

Session 5: training mindfulness in relationship; accepting thoughts and actions of self and spouse as they are; training basic acceptance; lack of judgment of self and spouse; training meta-meditation and giving homework.

Session 6: training that thoughts are not real and they are not good or bad and are just thought; training lack of fighting and logical encounter, along with acceptance and kindness to thoughts, making balance between thoughts and emotions; training inner smile technique; training 3 min record of thoughts and thanksgiving technique and looking everything from positive point of view and giving homework.

Session 7: training mindfulness in relationships; giving value to the relationship; the sense of appreciation and freedom through forgiving; mindfulness and meditation while facing problems; acceptance without positioning and awareness of thoughts and reactions and giving homework.

Session 8: meditation of body checking and review of last sessions.

\section{Results}

30 women have participated in this study as trials and out of these individuals, most of them were in the age range of 20-25 years old (36.6) and in terms of education level, most of the participants had a diploma degree $(60 \%)$ and had 2 children $(56.6 \%)$ and 5 years was passed from their marriage (46.6\%). Moreover, about $76.6 \%$ of women were housewives and others were employed.

\section{Analysis of Results}

Obtained results from descriptive indices related to depression and state-trait depression in two experimental and control groups have been presented in Table 1. To perform ANOVA, its presumptions are analyzed first of all. After adjusting pretest values, effectiveness of mindfulnessbased cognitive therapy in reducing depression of women victims of domestic violence was measured. According to obtained results in Table 2, $\mathrm{f}$-value is obtained to $\mathrm{F}=121.40$ that is significant in level of $p<001$ and this indicates effectiveness of mindfulness-based cognitive therapy in reduction of depression of women victims of violence. 
After adjusting pretest values, effect of mindfulness-based cognitive therapy on reducing state anxiety of women victims of violence was measured. According to obtained results in Table 3, $\mathrm{f}$-value of $\mathrm{F}=304.19$ is obtained that has been significant in level of $p<0.001$. This shows the effectiveness of mindfulness-based cognitive therapy on reducing state anxiety of women victims of violence. According to amount of the estimated effect of Eta and significance level, it could be mentioned that variance of state anxiety is discriminated by the independent variable of mindfulness-based cognitive therapy. After adjusting pretest values, the effectiveness of mindfulness-based cognitive therapy in reducing trait anxiety of women victims of domestic violence was measured. According to obtained results in Table $4, \mathrm{~F}$ is obtained to $\mathrm{F}=230.11$ that is significant in level of $p<0.01$. This shows the effectiveness of mindfulness-based cognitive therapy in reducing trait anxiety of women victims of violence. According to estimated effect of Eta and significance level, it could be mentioned that variance of trait anxiety could be determined by independent variable that is mindfulness-based cognitive therapy.

Table 1. Descriptive indices related to depression and state-trait anxiety scores

\begin{tabular}{lcccccccc}
\hline Variables & \multicolumn{3}{c}{ Experimental group } & \multicolumn{4}{c}{ Control group } \\
\cline { 2 - 8 } & $\mathrm{SD}$ & $\mathrm{M}$ & $\mathrm{SD}$ & $\mathrm{M}$ & $\mathrm{SD}$ & $\mathrm{M}$ & $\mathrm{SD}$ & $\mathrm{M}$ \\
\hline $\begin{array}{l}\text { Depression } \\
\text { Trait }\end{array}$ & 1.21 & 24.81 & 2.10 & 8.36 & 1.9 & 22.12 & 1.6 & 2.23 \\
$\begin{array}{l}\text { anxiety } \\
\begin{array}{l}\text { State } \\
\text { anxiety }\end{array}\end{array}$ & 3.91 & 580.6 & 4.20 & 47.60 & 4.20 & 56.21 & 4.90 & 53.12 \\
\hline
\end{tabular}

Table 2. Summary of MACOVA of depression scores

\begin{tabular}{lcccccc}
\hline $\begin{array}{l}\text { Statistical } \\
\text { indices }\end{array}$ & $\begin{array}{c}\text { Sum of } \\
\text { squares }\end{array}$ & df & $\begin{array}{c}\text { Mean } \\
\text { squares }\end{array}$ & F & Sig & Eta \\
\hline Pretest & 39.81 & 1 & 39.81 & 240.13 & 0.001 & 0.350 \\
Group & 191.28 & 1 & 191.28 & 114.40 & 0.001 & 0.711 \\
Error & 62.28 & 27 & 1.48 & & & \\
\hline
\end{tabular}

Table 3. Summary of MACOVA of state anxiety

\begin{tabular}{lcccccc}
\hline $\begin{array}{l}\text { Statistical } \\
\text { indices }\end{array}$ & $\begin{array}{c}\text { Sum of } \\
\text { squares }\end{array}$ & df & $\begin{array}{c}\text { Mean } \\
\text { squares }\end{array}$ & F & Sig & Eta \\
\hline Pretest & 1421.21 & 1 & 1421.21 & 514.24 & 0.001 & 0.821 \\
Group & 621.24 & 1 & 621.24 & 401.17 & 0.001 & 0.790 \\
Error & 60.81 & 27 & 2.91 & & & \\
\hline
\end{tabular}

Table 4. Summary of MANCOVA of trait anxiety

\begin{tabular}{lcccccc}
\hline $\begin{array}{l}\text { Statistical } \\
\text { indices }\end{array}$ & $\begin{array}{c}\text { Sum of } \\
\text { squares }\end{array}$ & $\begin{array}{c}\text { df } \\
\text { squares }\end{array}$ & F & Sig & Eta \\
\hline Pretest & 823.96 & 1 & 823.96 & 429.27 & 0.001 & 0.890 \\
Group & 421.41 & 1 & 421.41 & 312.49 & 0.001 & 0.756 \\
Error & 49.64 & 27 & 49.64 & & & \\
\hline
\end{tabular}

\section{Discussion}

The present study has been conducted to investigate the effectiveness of mindfulness-based cognitive therapy in reducing depression, state-trait anxiety of women victims of domestic violence in Tehran. Obtained results from this study showed that mindfulness-based cognitive therapy can affect reducing depression and state-trait anxiety of women victims of violence $(\mathrm{p}<0.001)$. These results have been in consistence with findings of de Bruin et al. ${ }^{23}$ and Kohls et al. ${ }^{24}$ and also with findings of Solati et al. ${ }^{25}$ showing that training mindfulness can affect physical and psychological symptoms of patients with Irritable Bowel Syndrome, so that this intervention method can reduce anxiety. The result has been also in consistency with findings of Zeidan et al. ${ }^{26}$ showing that training mindfulness can lead to reduction of pain and anxiety and with findings of Evans et al. ${ }^{18}$ showing effect of mindfulness-based cognitive therapy on symptoms of anxiety and depression and with findings of Williams et al. ${ }^{27}$ showing that mindfulness-based cognitive therapy can affect patients with relapse of depression and with findings of studies in field of effectiveness of mindfulness-based therapies showing that such therapies can affect physical and mental symptoms of depression ${ }^{28}$ and anxiety ${ }^{29,30}$ and with findings of Ma and Teasdale ${ }^{19}$, Hartmann et al. ${ }^{16}$ (2012) showing that mindfulness based on stress reduction can have positive and longterm effect on reduction of emotional distress (anxiety and depression) in types of chronic diseases. In regard to discriminating effect of mindfulness-based cognitive therapy in reducing depression and anxiety of women victims of domestic violence, it could be mentioned that change in negative thoughts and beliefs, controlling cognitive dysfunctions with presence of mind and having a mind without judgment can decline sense of distress and worry in patients and enhance sense of having control on affairs of life. 


\section{Conclusion}

Obtained results from this study showed that mindfulnessbased cognitive therapy can lead to a reduction of depression and anxiety in women victims of violence.

Following items can be limitations of this study:

small size of sample and that all sample individuals were female.

\section{Acknowledgments}

The authors would like to appreciate all patients participated in this study.

\section{References}

1. Scribano PV, Stevens J, Kaizar E, NFP-IPV Research Team. The effects of intimate partner violence before, during, and after pregnancy in nurse visited first time mothers. Maternal and Child Health Journal. 2013 Feb 1; 17(2):307-18.

2. Thoits PA. Self, identity, stress, and mental health. In: Aneshensel CS, Phelan JC, Bierman A, editors. Handbook of the Sociology of Mental Health. 2nd ed. 2013; 1(4):357-77.

3. Moracco KE, Runyan CW, Bowling JM, Earp JA. Women's experiences with violence: a national study. Womens Health Issues. 2007; 17(1):3-12.

4. Coker AL, Westone R, Creson DL, Justice B, Blakeney P. PTSD symptoms men and women survivors of intimate partner violence: the role of risk and protective factors. Violence Victims. 2005; 20(6):625-43.

5. Lipsky S, Filds CA, Caetano R, Larkin GL. Posttraumatic stress disorders symptomatology and comorbid depressive symptoms among abused women referred from emergency department care. Violence Victims. 2005; 20(6):645-59.

6. Camp Bell J, Rose L. Depression in Battered women. Journal of American Medical Women Association. 1996; 51(3):160-70.

7. Houry D, Kaslow NJ, Thompson MP. Depression symptoms in women experiencing intimate partner violence. Journal of Interpersonal Violence. 2005; 20(11):1467-77.

8. Gilroy H, Nava A, Maddoux J, McFarlane J, Symes L, Koci A, Fredland N. Poverty, partner abuse, and women's mental health: new knowledge for better practice. Journal of Social Service Research. 2015 Mar 15; 41(2):145-57.

9. Ghahari Sh. , Bolhari, G Atef Vahid, M. Ahmadkhaniha, H, Panaghi, L \& Yousefi, H. Prevalence of Spouse Abuse, and Evaluation of Mental Health Status in FemaleVictims of Spousal Violence in Tehran. Iranian Journal of Psychiatry and Behavioral Sciences (IJPBS), Volume 3, Number 1, Spring and Summer 2009: 50-56 .

10. Bradley R, Schwartz AC, Kaslow NJ. Posttraumatic stress disorder symptoms among low-income, African American women with a history of intimate partner violence and suicidal behaviors: self-esteem, social support, and religious coping. J truma stress. 2005; 8(6).

11. Cooper VR. Diagnostic and statistical manual of mental disorders. 5th ed. London: Karnac. 2014.

12. Omidvari S, Azin A, Montazeri A, Sadighi J, Jahangiri K, Aeenparast A. Trait anxiety among Iranians: a nationwide study. Payesh. 2011; 10(3):373-80.

13. Sadock BJ, Sadock VA, Ruiz P. Kaplan and Sadock's Synopsis of Psychiatry: Behavioral Sciences/ Clinical Psychiatry. 11th ed. USA: LWW; 2014.

14. Potek R. Mindfulness as a school-based prevention program and its effect on adolescent stress, anxiety and emotion regulation [PhD thesis]. ProQuest LLC: New York University; 2012.

15. Ma SH, Teasdale, JD. Mindfulness-based cognitive therapy for depression: replication and exploration of differential relapse prevention effects. Journal of Consulting and Clinical Psychology. 204; 72:31-40.

16. Hartmann M, Kopf S, Kircher C, Faude-Lang V, Djuric Z, Augstein F, Friederich H-C, et al. Sustained effects of a mindfulness-based stress reduction intervention in type 2 diabetic patients. Diabetes Care. 2012; 35(5):945-7. DOI: $10.2337 / \mathrm{dc} 11-1343$

17. Beck AT, Epstein N, Brown G, Steer R. Anxiety inventory manual. San Antonia, TX: The Psychological Corporation. 1996.

18. Evans S, Ferrando S, Findler M, Stowell C, Smart C, Haglin D. Mindfulness-based cognitive therapy for generalized anxiety disorder. J Anxiety Disord. 2008; 22(4):716-21.

19. Hashemi Z, Hashemi Nosrat-abad T. The effectiveness of meta cognitive therapy on major depression disorder: a case report. Journal of Clinical Psycology. 2010 Oct 15; 2(3):85-97.

20. Biabangard E. How to promote self- respect in children and adolescents. Tehran: Association of Parents and Educators. 2005.

21. Tol A, Pourreza A. Study of pre and post anxiety of coronary artery bypass graft surgery inpatients in hospitals affiliated with Tehran University of medical sciences. Hospital Journal. 2010; 8(3,4):43-8.

22. Mahram, B. Anxiety Exam Guide (overt and covert) Spielberger, Mashhad: the Faculty of Education and Psychology. 1993.

23. De Bruin, E. I., Topper, M., Muskens, J. G., Bögels, S. M., \& Kamphuis, J. H. Psychometric properties of the Five Facets Mindfulness Questionnaire (FFMQ) in a meditating and a non-meditating sample. Assessment, 2012; 19(2): 187-197.

24. Kohls N, Sauer S, Walach H. Facets of mindfulness-results of an online study investigating the Freiburg mindfulness inventory. Personality Individual Differences. 2009; 46:224-30.

25. Solati Dehkordi K, Nikfarjam M, Sanaei S. Effectiveness 
of mindfulness-based stress reduction training and drug therapy on quality of life in patients with irritable bowel syndrome in Shahrekord. Life Science Journal. 2014; 11(9):445-9.

26. Zeidan F, Johnson SK, Diamond BJ, David Z, Goolkasian P. Mindfulness meditation improves cognition: evidence of brief mental training. Conscious Cognition. 2010; 19(2):597-605.

27. Williams JM, Teasdale JD, Segal ZV, Soulsby J. Mindfulness-based cognitive therapy reduces over general autobiographical memory in for merely depressed patients. J Abnormal Psychology. 2000; 109(1):150-55.
28. Melyani M, Allahyari A, Azad-Fallah P. Mindfulness based cognitive therapy versus cognitive behavioral therapy on residual symptoms in recurrent depression. J Behavior Science. 2013; 7:17-8.

29. Golpourchamarkohi R, Mohammadamini Z. The efficacy of mindfulness based stress reduction on mindfulness and assertiveness of students with test anxiety. J School Psychology. 2012; 1:82-100.

30. Narimani M, Ariapooran S, Abolghasemi A. The comparison of the effectiveness of mindfulness and emotion regulation training on mental health in chemical weapon victims. Journal of Clinical Psychology. 2011; 2: 61- 71(Persian). 